\title{
Garantía convencional y garantía legal: una jerarquía dispersa y temperada
}

\author{
Íñigo de la Maza Gazmuri*
}

\section{RESUMEN}

Este trabajo intentará encontrar una forma de organizar la espinosa convivencia que existe en la Ley $N^{\circ} 19.496$ entre la garantía legal y las garantías de los proveedores. Esta forma consiste en establecer una cierta jerarquía y determinar bajo qué condiciones debiese funcionar.

Garantía legal - garantía convencional - disconformidad material

\section{Legal and conventional warranty: dispersed and tempered bierarchi}

\begin{abstract}
This article intends to figure out a way to organize the thorny coexistence of legal and commercial warranties within consumers law in Chile. The suggested way consists in setting out a bierarchy between them and determine under which conditions should work.
\end{abstract}

Legal warranty - comercial warranty - lack of conformity

* Licenciado en Ciencias Jurídicas y Sociales, Universidad de Chile. Abogado. Doctor en Derecho, Universidad Autónoma de Madrid, España. Profesor Investigador Facultad de Derecho, Universidad Diego Portales, Chile. Correo electrónico: inigo.delamaza@udp.cl.

Este artículo se enmarca en el Proyecto Fondecyt regular $\mathrm{N}^{\circ}$ 1171251. Agradezco la colaboración en tareas de investigación de Felipe Fernández Ortega y Nicolás Montes Serrano, cuyo trabajo demuestra que cualquier esfuerzo en formar ayudantes es un esfuerzo que vale la pena.

Artículo recibido el 16.07.2019 y aceptado para su publicación el 11.12.2019. 


\section{INTRODUCCIÓN}

E n el ámbito nacional existen dos extremos de los que conviene mantenerse alejado cuando se discute acerca de la tutela de los consumidores frente a ciertos supuestos de disconformidad material. El primero de ellos consiste en afirmar que el consumidor siempre puede optar por cualquiera de los remedios que dispone el artículo $20^{\circ}$ de la Ley $\mathrm{N}^{\circ} 19.496$. El segundo extremo consiste en señalar, sin las debidas cualificaciones, que, si existe una garantía convencional, el consumidor siempre debe agotar las posibilidades que esta ofrece antes de acudir a la garantía legal.

Ninguna de las dos afirmaciones es correcta, o al menos eso es lo que intenta demostrar este trabajo. En primer lugar, resulta perfectamente plausible en términos jurídicos que se limite la posibilidad del consumidor de exigir la resolución del contrato y se le exija, en primer lugar, solicitar la reparación o sustitución. En segundo lugar, parece completamente absurdo que se exija al consumidor agotar las posibilidades de la póliza cuando estas no son razonables.

Algún sector especialmente autorizado de la doctrina ha estimado que la triple opción que concede el artículo $20^{\circ}$ a los consumidores siempre se encontraría disponible, no obstante la existencia de una garantía convencional. Por otra parte, el inciso $9^{\circ}$ del artículo $21^{\circ}$ exige al consumidor agotar las posibilidades de la póliza antes de acudir a la garantía legal. Sin embargo, ambas afirmaciones deben matizarse.

La primera de ellas porque los argumentos que se utilizan para justificar que la triple opción siempre está disponible para el consumidor no son, en mi opinión al menos, suficientemente persuasivos. La segunda, porque resulta completamente evidente que no cualquier término en una póliza resulta aceptable, particularmente teniendo en cuenta el carácter tutelar de la Ley $\mathrm{N}^{\circ} 19.496$.

El propósito de este trabajo, entonces, es doble. De una parte, se trata de demostrar que la garantía convencional puede primar sobre la garantía legal en términos de no permitir al consumidor servirse inmediatamente de la terminación del contrato, sino que deberá solicitar la reparación o sustitución del producto. De otra parte, se trata de advertir que esto no significa que cualquier garantía convencional produzca este efecto.

El orden en que procedo es el siguiente. En primer lugar, intento advertir en qué consiste la discusión que me interesa. A continuación, presento los argumentos que se han dado para justificar la primacía del derecho de opción que confiere la garantía legal: irrenunciabilidad, el absurdo que supondría que la garantía convencional protegiera menos que la legal y las dificultades prácticas que esto entrañaría. En tercer lugar, muestro que la irrenunciabilidad no debe entenderse como una limitación a la primacía convencional. En cuarto, sugiero que, si se mira como un régimen especial de tutela del consumidor, no necesariamente resulta ser absurda la primacía. En fin, en quinto lugar muestro que las dificultades prácticas más bien aconsejan establecer límites a las garantías convencionales.

En definitiva, lo que intento demostrar es que el juego de los dos tipos de garantías permite advertir una cierta jerarquía de los remedios del consumidor frente a determinados supuestos de disconformidad material. Se trataría de una jerarquía cuya disciplina 
se encuentra dispersa entre las normas de la garantía legal y convencional y, a la vez, se vería temperada por las limitaciones que se imponen a los proveedores al momento de establecer sus garantías convencionales.

\section{LA PREGUNTA Y LA OPINIÓN DE LA DOCTRINA}

\section{Dos sentencias y una pregunta}

La sentencia de la Corte de Apelaciones de Concepción de 15 de abril de $2009^{1}$ se pronuncia acerca de la convivencia entre la garantía legal y la garantía convencional en los siguientes términos:

“Tratándose de productos respecto de los cuales se haya dado una póliza de garantía voluntaria por el fabricante o proveedor, el derecho del consumidor a exigir algunos de los derechos conferidos por el artículo 20 de la Ley ya mencionada, puede ejercerse cuando ya se haya hecho uso, al menos una vez, de los mecanismos que contemple la póliza para solucionar la deficiencia y estos no hayan dado resultado satisfactorio o se presenten nuevas fallas.

En otras palabras, en caso de existir una garantía voluntaria, el consumidor antes de ejercer los derechos descritos en el artículo 20 de la Ley $\mathrm{N}^{\circ} 19.496$, debe hacer exigible esta garantía voluntaria ante quien corresponda y agotar las posibilidades que ofrece, todo ello conforme a los términos establecidos en la misma póliza entregada por el proveedor.

6. Que es necesario tener presente que la regla establecida en el artículo 21 inciso $6^{\circ}$ de la Ley $\mathrm{N}^{\circ} 19.496$, significa que la garantía legal y la garantía convencional son compatibles, pero en tal caso el consumidor, antes de ejercer alguno de los derechos que le confiere el artículo 20, deberá hacerla ante quien corresponda y agotar las posibilidades que ofrece, conforme a los términos de la póliza.

Lo anterior implica, que respecto de los artículos defectuosos vendidos con una garantía voluntaria, el consumidor no puede ejercer los derechos conferidos por el artículo 20 de la ley citada precedentemente, sin previo ejercicio de la garantía del proveedor".

Por su parte, la sentencia de la Corte de Apelaciones de Valparaíso, en una sentencia de 3 de febrero de $2017^{2}$ y conociendo acera de la misma cuestión que la sentencia anterior, en los siguientes términos:

\footnotetext{
${ }^{1}$ Corte de Apelaciones de Concepción, 15.04.2009, rol 254-2008.

${ }^{2}$ Corte de Apelaciones de Valparaíso, 03.02.2017, rol 568-2016.
} 
"Undécimo: Que de acuerdo a lo expuesto precedentemente, a juicio de estos sentenciadores, con la actuación de la querellante, se salvaguardó, debidamente, la disposición del artículo 21 de la ley mencionada, atendido a que no puede pedírsele al consumidor que agote en todos sus grados la garantía convencional que lo favorece, pues si así fuere estaría claramente en desventaja frente a la garantía legal, la que sin lugar a dudas le ofrece un rango mucho mayor de indemnización frente a un contrato, en que claramente el consumidor suele estar en disminución ante el ente asegurador.

Duodécimo: Que en virtud de esa actuación, y dada la reiteración en hacer uso por parte de la querellante de la garantía convencional de la que era beneficiaría, a la actora en ese estado de cosas, le cabía claramente la posibilidad de invocar, como lo hizo, la garantía legal y pedir la reposición o devolución del precio, como lo faculta el artículo 20, en su letra e) de la ley en comento (...)”.

Se trata de extractos extensos, sin embargo, cumplen con dos funciones importantes en este trabajo. La primera de ellas consiste en ilustrar la cuestión que lo ocupa. La segunda consiste en sugerir cuál es la tesis que defiende este trabajo.

Por lo que toca a lo primero. Como puede advertirse, ambas sentencias se refieren a un ángulo de la espinosa convivencia de la garantía legal y la convencional en la Ley $\mathrm{N}^{\mathrm{0}} 19.496^{3}$. Se trata de determinar si -y bajo qué condiciones- la garantía convencional prefiere a la legal o bien si el derecho de opción que establece la garantía legal siempre está disponible, no obstante la existencia de una garantía convencional que establezca únicamente la reparación del producto o, con menor frecuencia, su sustitución.

La cuestión se plantea pues, como ha sugerido un autor, la regla general es que las pólizas de garantía se limiten a la reparación y, únicamente de manera excepcional, se extiendan al reemplazo del producto $^{4}$, sin considerar, entonces, la devolución del

${ }^{3}$ Señalo que se trata de un ángulo porque la convivencia de la garantía legal y convencional genera otros problemas que no voy a considerar en este trabajo, así, por ejemplo, cuestiones relativas al carácter vinculante de la opción para el consumidor, ver Corte de Apelaciones de La Serena, 09.02.2016, rol 103-2015, resolviendo que una vez ejercida la opción por la convencional no se puede modificar, las limitaciones a los bienes usados por ejemplo la sentencia de la Corte de Apelación de Concepción, 29.05.2013, rol 359-2012 o la suspensión de la prescripción, ver, Corte de Apelaciones de Santiago, 21.07.2010, rol 11857-2009.

${ }^{4}$ Ver Corral, 2011, p. 415. No obstante, existen casos de esta manera en una sentencia de la Corte de Apelaciones de Rancagua, 22.11.2011, rol 93-2011, donde la Corte considera que no se burla el derecho que confiere a los consumidores el artículo $20^{\circ}$ de la Ley $\mathrm{N}^{\circ} 19.496$ mediante pólizas que permitan el reemplazo de piezas defectuosas. En palabras de la Corte:

"Que la posibilidad de que se burle el derecho de los consumidores mediante el expediente de la existencia de pólizas de garantía que impidan optar derechamente por la devolución del producto, no existe ni en general ni en el caso particular. Lo primero, porque si una vez reparado no resulta el bien enteramente funcional, tal como debe serlo uno nuevo, opera el derecho general del señalado articulo 20 de la Ley de Protección al Consumidor y, en cuanto a lo particular de este caso, aquí de lo que se ofrecía era reemplazar una pieza por otra original, y no arreglar simplemente la defectuosa, de suerte tal que con aquel reemplazo el refrigerador venia a resultar equivalente por entero a uno nuevo y sin uso, de manera que ha sido la propia cliente, al negarse a esa solución, probadamente ofrecida por su vendedor, la que ha impedido tanto el co- 
precio 5 . De esta manera, la discusión puede formularse en términos más sencillos: existiendo una garantía convencional ¿debe el consumidor acudir a ella en primer lugar -específicamente a la reparación del producto o su reemplazo- o, en cambio, sin hacerlo, puede optar por alguno de los otros remedios que le franquea la garantía legal, específicamente la restitución del precio?

Como se verá, en el ámbito nacional, la respuesta no ha sido pacífica y, en general, la doctrina más autorizada parece estimar que la garantía legal prefiere a la convencional en términos que el consumidor siempre tiene derecho a la opción que le confiere la garantía legal. Respecto de los tribunales, parece existir una cierta tendencia a preferir la garantía convencional por sobre la legal. ${ }^{6}$

La tesis que se defiende en este trabajo es que, en la medida en que la garantía convencional permita al proveedor, bajo condiciones razonables, la reparación o la sustitución, esta prefiere a la opción de devolución del precio a que se refiere el artículo $20^{\circ}$.

La segunda sentencia permite intuir algo como eso, pues, si bien es cierto que se permite a la compradora acceder a la garantía legal, esto tiene lugar una vez que intentó la reparación disciplinada por la garantía convencional.

Pues bien, una mirada a la Ley $\mathrm{N}^{\circ} 19.496$ muestra que la garantía convencional que interesa a este trabajo alude a un cierto acuerdo entre el proveedor y el consumidor, en virtud de ello, el primero concede al segundo ciertos remedios frente a supuestos de disconformidad cualitativas. Lo más frecuente será que el remedio corresponda a la reparación del producto. Asimismo, la garantía legal corresponde a un régimen de tutela del consumidor frente a la presencia del mismo tipo de anomalías, sin embargo, esta vez se concede al consumidor el derecho de optar, junto con la indemnización de perjuicios, por la reparación, la sustitución de la cosa o la devolución del precio.

rrecto funcionamiento del bien que adquirió, como su reemplazo o la restitución del precio, si la reparación no hubiere resuelto el problema".

${ }^{5}$ Ver Corral, 2011, p. 415 y Barrientos, 2016, p. 241-242.

${ }^{6}$ Ver, por ejemplo, Corte de Apelaciones de Santiago, 19.05.2016, rol 272-2016, Corte de Apelaciones de Santiago, 6.10.2015, rol 1059-2015. En ésta se lee:

"Que, en la especie, el vehículo antes indicado, estaba amparado por la garantía de compra, la que fue ofrecida en reiteras oportunidades, lo que no fue aceptado por el consumidor, por lo que, la norma legal antes indicada, le impide al consumidor ejercer los otros derechos, sin antes hacer efectiva la garantía que goza el producto".

En el mismo sentido, la sentencia de la Corte de Apelaciones de La Serena, 2.12.2012, rol 106-2010:

"Que, por otra parte, si bien el artículo 20 de la Ley N 19.496, dispone que sin perjuicio de la indemnización por los daños ocasionados, el consumidor podrá optar entre la reparación gratuita del bien o previa restitución, su reposición o la devolución de la cantidad pagada"; ello en los casos señalados entre otros, en la letra c) cuando cualquier producto por diferencias de fabricación, elaboración, piezas, estructura, calidad, no sea enteramente apto para el uso al que está destinado; no es menos cierto que el artículo 21 de la Ley mencionada en su inciso noveno precisa "Que tratándose de bienes amparados por una garantía otorgada por el proveedor, el consumidor antes de ejercer alguno de los derechos que le confiere el artículo 20, deberá hacerla efectiva ante quien corresponda y agotar las posibilidades que ofrece conforme a los términos de la póliza".

Ver también Corte de Apelaciones de La Serena, 9.02.2016, rol 103-2015, y Corte de Apelaciones de Valdivia, 8.06.2011, rol 64-2011. 


\section{La discusión}

Como ya ha quedado dicho la respuesta frente a la pregunta acerca de si la garantía convencional prefiere la opción que le confiere la legal o si el consumidor siempre tiene derecho a optar no ha sido pacífica. Antes de exponer las distintas opiniones convendrá precisar por qué la pregunta ha resultado desafiante. Y conviene hacerlo porque, a primera vista al menos, la respuesta parecería clara.

Para advertirlo es necesario prestar atención al texto del inciso primero del artículo $20^{7}$, su letra e $)^{8}$ y luego el inciso noveno del artículo $21^{9}$, todos ellos de la Ley $\mathrm{N}^{\mathrm{o}} 19.496$.

Al combinar estas reglas, aparece que la convivencia entre ambas garantías funciona en términos tales que (1) si existe una garantía otorgada por el proveedor (2) el consumidor deberá agotarla antes de acudir a la garantía legal. (3) El agotamiento de la garantía, sin embargo, no es algo que determine el proveedor a su arbitrio; luego de haberse hecho efectiva la garantía y prestado el servicio técnico, el consumidor puede servirse de la garantía legal para solicitar la restitución del precio si aún subsisten las deficiencias o surgen otras.

Según me parece, a primera vista al menos, lo que indica la lectura conjunta de las normas es que la garantía convencional prefiere a la legal. Por lo mismo resulta más útil explorar la posición de quienes estiman que la garantía legal prefiere a la convencional que la de quienes siguen el tenor literal de las normas. Por lo demás, en los primeros existe un valioso intento de argumentación; los segundos, en cambio, se limitan más bien a reproducir las reglas sin añadir mucho más ${ }^{10}$.

La defensa más decidida acerca de la primacía de la garantía legal ha corrido por cuenta del profesor Hernán Corral ${ }^{11}$. Sus argumentos, según yo los entiendo, son los siguientes. En primer lugar, señala que existiría una contradicción en la Ley N 19.496 si, por una parte, se reconociera al consumidor la facultad de optar (art. $20^{\circ}$ ) y, por otra

7 "En los casos que a continuación se señalan, sin perjuicio de la indemnización por los daños ocasionados, el consumidor podrá optar entre la reparación gratuita del bien o, previa restitución, su reposición o la devolución de la cantidad pagada”.

8 "Cuando después de la primera vez de haberse hecho efectiva la garantía y prestado el servicio técnico correspondiente, subsistieren las deficiencias que hagan al bien inapto para el uso o consumo a que se refiere la letra c). Este derecho subsistirá para el evento de presentarse una deficiencia distinta a la que fue objeto del servicio técnico, o volviere a presentarse la misma, dentro de los plazos a que se refiere el artículo siguiente".

9 “Tratándose de bienes amparados por una garantía otorgada por el proveedor, el consumidor, antes de ejercer alguno de los derechos que le confiere el artículo 20, deberá hacerla efectiva ante quien corresponda y agotar las posibilidades que ofrece, conforme a los términos de la póliza”.

${ }^{10}$ Ver, por ejemplo, Aimone, 2013, p. 48. Sandoval, 2016 , p. 54, Fernández, 2003, p. 38. Una conspicua excepción, sin embargo, es el trabajo del profesor Jaime Lorenzini, quien señala tres razones para preferir la garantía convencional: la primera de ellas consistiría en que el legislador incentivó a los proveedores a ofrecer garantías convencionales, la segunda es el propio tenor del artículo 21 inc. 9; en fin, la tercera razón es que el legislador conjuró algunos de los riesgos que entraña la preferencia de la garantía convencional en términos que el consumidor únicamente debe proceder una vez al servicio técnico (LORENZINI, 20I5, pp. 700-701).

${ }^{11}$ Corral, 2011, pp. 415-421. 
(art. $21^{\circ}$ ) se restringiera. Añade que, el artículo $4^{\circ}$ de la Ley $\mathrm{N}^{\circ} 19.496$ establece que los derechos que reconoce al consumidor son irrenunciables e indica que:

"La irrenunciabilidad del artículo $4^{\circ}$ se estaría vulnerando, ya que, el consumidor, al aceptar la garantía que le concede mayor abundancia el proveedor, estaría renunciando tácita o incluso fictamente al derecho de opción que le confiere expresamente la ley: 'el consumidor podrá optar (...)"'12.

A este argumento que en ocasiones han acogido los tribunales ${ }^{13}$, agrega que sería absurdo que el consumidor quedara menos protegido por una garantía convencional que por la legal y la presencia de numerosas dificultades prácticas:

“muchas veces el consumidor quedará atrapado en un servicio técnico ineficiente, que demora en ir a revisar el bien o a retirarlo y que luego retrasa la reparación, justamente porque el bien no tiene fácil arreglo”.

En tercer lugar, estima el profesor Corral que de la historia de la ley no puede inferirse el significado del artículo 20 inciso $9^{\circ}$ a que pareciera conducir su tenor lite$\mathrm{ral}^{14}$. Indica que no hay mayores antecedentes que expliquen la introducción de esta regla, que no se encontraba en el Mensaje del Poder Ejecutivo y fue incorporada por la Comisión de Economía de la Cámara de Diputados. En esa instancia, la norma habría sido pensada para los casos en que el consumidor optara por la reparación y no lo privaría de los demás medios de tutela propios de la garantía legal ${ }^{15}$.

Finalmente, en cuarto lugar, estima que existirían dificultades prácticas; señala el profesor Corral lo siguiente:

"A todas estas incongruencias normativas, deben añadirse evidentes dificultades prácticas: muchas veces el consumidor quedará atrapado en un servicio técnico ineficiente, que demora en ir a revisar el bien o a retirarlo y que luego retrasa la reparación, justamente porque el bien no tiene fácil arreglo.

El consumidor se ve indefenso ya que solo podría reclamar judicialmente cuando se hayan 'agotado las posibilidades que ofrece la garantía'. Esta será necesario acreditarlo en juicio, para luego tener que demandar la elección de la reposición o la devolución. Aunque se permita la acumulación de acciones, deberá acreditarse el agotamiento de las posibilidades, para que pueda el juez considerar la segunda acción que invoca la garantía legal" ${ }^{16}$.

\footnotetext{
12 Corral, 2011, pp. 416-417.

${ }^{13}$ Así, por ejemplo, en una sentencia de la Corte de Apelaciones de San Miguel, 5.10.2012, rol 967-2012.

${ }^{14}$ Corral, 2011, p. 417-421.

15 Corral, 2011, p. 419-420.

${ }^{16}$ Corral, 2011, p. 417.
} 
¿Cómo entiende, entonces, el profesor Corral el inciso $9^{\circ}$ del artículo 21? De la siguiente manera:

"La norma lógicamente se pone en el caso de que el consumidor haya sido provisto de una garantía voluntaria. De este modo señala que 'antes de ejercer alguno de los derechos que le confiere el artículo 20' (la garantía legal), puede hacer valer la garantía voluntaria, caso en el cual 'deberá hacerla efectiva ante quien corresponda', es decir, ante el proveedor directo o ante el fabricante que la haya otorgado, y luego deberá agotar las posibilidades que ofrece conforme a los términos de la póliza. Es decir, el 'deberá' no apunta a la opción de la reparación, sino a que, si opta por la reparación no puede revocarla sino que debe agotar sus posibilidades, en los términos estipulados en la póliza.

Esta intelección de la norma pone a salvo el derecho del consumidor, aun en presencia de una garantía, de pedir al vendedor la reposición o la devolución del precio. Si opta por la reparación debe invocar, no la garantía legal, sino la voluntaria y agotar sus posibilidades. Si aun así subsisten las deficiencias o el bien tiene una falla distinta, nuevamente se abrirá para él la opción de pedir reposición o la devolución del precio conforme a la letra e) del artículo 20 LPC"17.

La segunda opinión que conviene tener en cuenta es la de la profesora Francisca Barrientos. Señala esta autora que:

"no resulta posible justificar desde la óptica de la legislación protectora del consumidor la interpretación que restrinja los derechos emanados de la garantía legal cuando se ha suscrito una póliza convencional (o del fabricante)". ${ }^{18}$

Añade que si existe una cláusula que los restrinja, esta sería abusiva. En segundo lugar, cita a Corral en el texto que aquí ya se ha examinado. A continuación se refiere a la legislación española, italiana y colombiana para señalar que, en estas, la garantía convencional es más bien suplementaria de la legal. En fin, en cuarto lugar, señala que existen algunas sentencias en las que se dispone que el consumidor no debería agotar todas las medidas a que se refiera la garantía convencional, sino que se aplicaría el artículo $20^{\circ}$ letra e). ${ }^{19}$

La conclusión de esta autora es la siguiente:

"En definitiva, la forma de compatibilizar la garantía legal con la ofrecida por el vendedor garante estará dada por la suspensión de la primera mientras está vigente la segunda, y por la recta interpretación de la expresión agotar los términos que

\footnotetext{
${ }^{17}$ Corral, 2011, p. 421.

18 BARrientos, 2016, p. 248-249.

19 BARrientos, 2016, p. 249-250.
} 
ofrece. La debida interpretación debe ser la propuesta por la doctrina, es decir, debe ejercerse una vez un derecho de la póliza convencional, idea que sería coherente con la solución judicial al confrontarlo con el articulo 20 letra e)" 20.

Sin embargo, algunas páginas antes de esa conclusión, Barrientos señala que:

“(...) Si existe una cláusula que los restrinja o limite, la garantía debería calificar como nula por lo dispuesto en el artículo 16 letra g). En este sentido, los derechos de la garantía legal son normas de orden público irrenunciables para el consumidor (artículo $\left.4^{\circ}\right)^{\prime 21}$.

Entonces, habría que entender que la profesora Barrientos entiende que la cláusula de una garantía convencional que impida la devolución del precio -uno de los remedios de la garantía legal- estableciendo la reparación sería abusiva.

Pues bien, una mirada a las opiniones del profesor Corral y de la profesora Barrientos muestran que el primer argumento que justificaría que la garantía legal preferiría a la convencional en términos de que la opción que consagra la primera siempre estaría disponible se relaciona estrechamente con la irrenunciabilidad de los derechos que reconoce la LPC a los consumidores.

Como ya se ha visto, ambos sugieren que se vulneraría la irrenunciabilidad pues al aceptar la garantía convencional el consumidor estaría renunciando al derecho de opción que le confiere el artículo $4^{022}$.

En segundo lugar, el profesor Corral considera que la lectura que da preferencia a la garantía convencional llevaría a un absurdo y señala que:

"La ley se contradeciría a si misma al establecer que, en los casos del artículo 20, el consumidor podrá optar entre reparación, reposición o devolución, para enseguida negarle ese derecho cuando haya aceptado, sin saber que con ella quedaba menos protegido, que se le entregaba una garantía voluntaria"23.

En fin, como ya ha quedado dicho, el profesor Corral se refiere a ciertas dificultades prácticas que entrañaría esta interpretación, según esta, la garantía convencional preferiría a la legal.

\footnotetext{
${ }^{20}$ Barrientos, 2016, p. 252.

${ }^{21}$ Barrientos, 2016, p. 249.

22 Corral, 2011, p. 416-417.

${ }^{23}$ Corral, 2011, p. 416.
} 


\section{UNA CIERTA JERARQUÍA}

Los tres argumentos - la irrenunciabilidad, el absurdo y las dificultades prácticasque se pueden extraer de las opiniones del profesor Corral y de la profesora Barrientos resultan, a primera vista, muy persuasivos ${ }^{24}$. Sin embargo, según me parece, los tres admiten una segunda mirada.

Al darles esa segunda mirada confío, a la vez, mostrar que resulta plausible sostener que (1) existe una cierta jerarquía en la Ley $\mathrm{N}^{\circ} 19.496$ respecto de los remedios que reconoce al consumidor frente a determinados supuestos de disconformidad material; (2) que esa jerarquía, por así decirlo, se encuentra dispersa entre la garantía legal y la convencional y (3) que se trata de una jerarquía temperada por las limitaciones de la garantía convencional. Estas cuestiones deberían aparecer al reconsiderar el argumento del absurdo y el de las dificultades prácticas. Sin embargo, antes de llegar a ellos resulta necesario, preliminarmente, considerar la cuestión de la irrenunciabilidad.

\section{El argumento de la irrenunciabilidad}

Para calibrar adecuadamente el argumento de la irrenunciabilidad de los derechos del consumidor exartículo $4^{\circ}$ de la Ley $\mathrm{N}^{\circ} 19.496$ convendrá comenzar advirtiendo que el hecho de que un derecho sea irrenunciable depende de dos circunstancias. La primera es que el ordenamiento jurídico reconozca la existencia de ese derecho, la segunda es que declare que no puede ser, digamos, abandonado mediante actos de autonomía privada.

A continuación, parece útil advertir que, para precisar el sentido en el que un derecho es irrenunciable, resulta imprescindible determinar la forma en que el ordenamiento jurídico reconoce ese derecho.

Así, por ejemplo, el artículo 153 dispone que: "La mujer no podrá renunciar en las capitulaciones matrimoniales la facultad de pedir la separación de bienes a que le dan derecho las leyes". Se trataría de una irrenunciabilidad sin cualificaciones; el legislador la establece sin ningún tipo de restricción.

Sin embargo, en ocasiones, la irrenunciabilidad opera con ciertas cualificaciones. Así lo muestra, en lo que aquí interesa, la LPC. Ya se ha visto que los derechos que reconoce esta ley a los consumidores son irrenunciables. Uno de esos derechos, según lo dispone el artículo $3^{\circ}$ letra e) es: "El derecho a la reparación e indemnización adecuada y oportuna de todos los daños materiales y morales en caso de incumplimiento de cualquiera de

${ }^{24}$ No considero la historia de la ley pues me parece que resulta poco concluyente. El profesor Corral, argumenta agudamente aquí (CORRAL, 2011, pp. 419-420), sin embargo, al consultar la historia de la Ley, lo cierto es que allí queda de manifiesto es que se cambió la expresión "podrá” por "deberá". Por otra parte, si bien fue iniciativa de la Cámara y no de la Comisión del Senado, lo cierto es que esta última lo mantuvo. En tercer lugar, que no se haya explicitado que aquí había un cambio de fondo es, en abstracto, un buen argumento, pero la calidad del proceso legislativo chileno, señaladamente con la LPC, impide desprender indubitadamente esa consecuencia. En fin, la opinión del senador Lavandero es un buen argumento, sin embargo, reconoce que la garantía legal es complementaria y supletoria de la convencional, no que la prefiere. 
las obligaciones contraídas por el proveedor". Por su parte, el artículo 16 letra e) de la misma ley dispone que: "No producirán efecto alguno en los contratos de adhesión las cláusulas o estipulaciones que:

e) Contengan limitaciones absolutas de responsabilidad frente al consumidor que puedan privar a este de su derecho a resarcimiento frente a deficiencias que afecten la utilidad o finalidad esencial del producto o servicio".

Lo que permite advertir este ejemplo es que el derecho a una reparación e indemnización adecuada de todos los daños materiales y morales es parcialmente renunciable. La razón es la siguiente. El artículo 16 letra b) declara abusivas ciertas cláusulas limitativas de responsabilidad ${ }^{25}$, por lo mismo, habrá que concluir que otras cláusulas limitativas son perfectamente válidas. Por definición una cláusula limitativa determina que no todos los perjuicios sufridos serán reparados, esa es precisamente su función.

Como puede verse, la técnica de establecer la irrenunciabilidad de un derecho y luego cualificarla no es desconocida para la regulación de las relaciones de consumo.

Según mi opinión esto es, precisamente, lo que hace el inciso $9^{\circ}$ del artículo 21, cualificar el derecho a opción del consumidor establecido en el artículo 20 de la Ley $\mathrm{N}^{\circ} 19.496$ determinando que la irrenunciabilidad de dicha opción quede cualificada por la existencia de una garantía convencional. Se trata, por lo demás, de una idea que ya había defendido el profesor Jaime Lorenizini ${ }^{26}$.

Si esto resulta ser correcto, entonces correcto ha de ser también que el argumento de la irrenunciabilidad no impide considerar una cierta primacía de la garantía convencional por sobre la legal.

2. El argumento del absurdo y la mirada a las garantías como componentes de un régimen de tutela del consumidor

Luego de considerar la cuestión de la irrenunciabilidad, el profesor Corral agrega:

“A todo ello hay que añadir el absurdo de que el consumidor resulte perjudicado cuando la intención de las partes, tanto la del proveedor como la del consumidor, ha sido la de brindar y obtener mayor protección. El absurdo llega al máximo si se considera la llamada garantía extendida en la que el consumidor paga una suma adicional para gozar de sus supuestos beneficios".

Se trata de un argumento intuitivamente poderoso. Pero no solo eso; si se mira un derecho como el español que ha resultado relevante en el diseño de la Ley $\mathrm{N}^{\circ} 19.496$, se

\footnotetext{
${ }^{25}$ Con una técnica absolutamente lamentable, como se han ocupado de advertirlo los profesores TAPIA Y VALDivia, 2002, p. 70, pero ese no es el tema aquí.

${ }^{26}$ LORENZINI, 2015, p. 699.
} 
descubre que el artículo 125 del Texto Refundido de la Ley General de Consumidores y Usuarios (TRLGDCU), bajo el título "garantía comercial adicional” se encuentra alineado con la opinión del profesor Corral. De esta manera en la letra c) de dicho artículo se exige que: "la garantía no afecta a los derechos legales del consumidor y usuario ante la falta de conformidad de los productos con el contrato".

Algo semejante sucede con la doctrina española. Así, por ejemplo, Avilés García ha sugerido que se trata de una garantía cuyo objeto consiste en mejorar el nivel de protección que reconoce la garantía legal del producto adquirido ${ }^{27}$. En el mismo sentido, Torrelles Torrea:

"En todo caso, esta garantía ha de implicar una mejora y ampliación de la protección que se le dispensa al consumidor a través del régimen de responsabilidad por la falta de conformidad, ya sea un mayor contenido de derechos (por ejemplo, conceder al consumidor la posibilidad de solicitar la rebaja del precio o la resolución como primeros remedios además de la reparación o sustitución), un alargamiento de plazos, que el garante sea una persona distinta a la del vendedor, etc." ${ }^{28}$.

Por su parte, la profesora Francisca Barrientos, afirma lo siguiente:

"Las legislaciones extranjeras han previsto de forma expresa que las pólizas convencionales o del fabricante no pueden imponer limitaciones a la garantía legal. En España, el TRLGDCU en el artículo 125 c) prohíbe que la garantía comercial afecte a los derechos legales del consumidor frente a la falta de conformidad" 29.

De esta manera, parece estar en lo cierto el profesor Corral cuando advierte que no resulta intuitivo que la garantía convencional reduzca la protección que dispensa la garantía legal; el argumento resulta particularmente persuasivo si se trata de una garantía extendida por la que se cobra ¿Cómo podría entenderse que alguien pagara por menor protección? El profesor Corral tiene razón: resultaría "absurdo"30.

Sin embargo, acaso de manera algo sorprendente, sea el mismo derecho español -y, en general el europeo basado en la Directiva 1999/44/CE del Parlamento Europeo y del Consejo, de 25 de mayo de 1999, sobre determinados aspectos de la venta y las garantías de los bienes de consumo (Directiva 99/44) - el que permita descubrir por qué, no obstante encontrarse plasmada con una técnica legislativa lamentable, la primacía de la garantía convencional respecto de la legal en la LPC no necesariamente conduzca a un absurdo.

27 Avilés García, 2009, p. 14.

${ }^{28}$ Torrelles, 2011, p. 1129. Añade Álvarez Moreno, 2006, p. 181 que la garantía legal únicamente alcanza a defectos coetáneos mientras la convencional podría cubrir los sobrevenidos.

29 BARRIENTOS, 2016, p. 250.

${ }^{30}$ Corral, 2011, p. 417. 
En otras palabras, efectivamente, el TRLGDCU y la Directiva 99/44 impiden que la póliza convencional o del fabricante establezca limitaciones a la garantía legal. Sin embargo, de allí no se sigue, necesariamente, un argumento que preste utilidad para defender la primacía de la opción propia de la garantía legal por sobre la convencional bajo cualquier circunstancia en la LPC. En realidad -esto es lo que quiero defenderpuede seguirse algo diverso y, hasta cierto punto contradictorio. La situación española -y europea en general- puede utilizarse para sostener que, con una torpeza digna de mejor causa, el legislador chileno intentó establecer una cierta jerarquía de remedios. Sin embargo, a diferencia del legislador español, no lo hizo, por así decirlo, al interior de la garantía legal, sino que la distribuyó entre esta y la garantía convencional.

Desenvolver esta idea aconseja comenzar con una breve consideración a la responsabilidad del vendedor y los derechos del consumidor y usuario del TRLGDCU que viene a trasponer a este respecto el artículo 3 de la Directiva 99/4431. Se trata de un artículo cuya extensión desaconseja transcribirlo, sin embargo, conviene prestar atención a lo que enseña su lectura, no solo acerca del derecho español de compraventa de consumo, sino acerca de todo el derecho europeo en este ámbito; y eso que enseña ha de resultar útil para planterarse la administración de la convivencia entre la garantía legal y la convencional en el ámbito nacional.

Lo primero que enseña el precepto es que existe una jerarquía entre los remedios que se ponen a disposición del consumidor frente a una falta de conformidad, en términos tales que, frente a una falta de conformidad, el consumidor debe acudir primero a los remedios que permiten corregir dicha falta, es decir, a la reparación o la sustitución ${ }^{32}$. El artículo 119 del TRLGDCU dispone, en lo que aquí interesa, las cosas de la siguiente manera:

“1. Si el producto no fuera conforme con el contrato, el consumidor y usuario podrá optar entre exigir la reparación o la sustitución del producto, salvo que una de estas dos opciones resulte objetivamente imposible o desproporcionada. Desde el momento en que el consumidor y usuario comunique al vendedor la opción elegida, ambas partes habrán de atenerse a ella. Esta decisión del consumidor y usuario se entiende sin perjuicio de lo dispuesto en el artículo siguiente para los supuestos en que la reparación o la sustitución no logren poner el producto en conformidad con el contrato".

Se trata de los "remedios de primer grado" ante una falta de conformidad ${ }^{33}$. En este supuesto, el consumidor puede optar por cualquiera de ellos. La finalidad de esta opción limitada es de conservar el contrato. Como sugiere Torrelles: "en este punto el

31 Antecedentes de la historia del precepto en Fenoy, 2009, pp. 236-240.

32 Esta jerarquía también puede notarse en el artículo 4:205 de los Principles of European Law Sales. Ver Principles of European Law. Study Group on a European Civil Code, Sales (PEL S), prepared by Hondius/ Heutger/Jeloschek/Sivesand/Wiewiorowska, 2008.

33 Ver Torrelles, 2011, p. 1091. 
legislador ha hecho prevalecer la seguridad de las transacciones (favor contractus) por encima de la confianza del consumidor en el mercado" 34 .

Los siguientes artículos del TRLGDCU -el 120- desarrolla el régimen jurídico de la reparación o sustitución del producto. Por su parte, el artículo 121 se refiere a la reducción del precio y la resolución en los siguientes términos:

"La rebaja del precio y la resolución del contrato procederán, a elección del consumidor y usuario, cuando este no pudiera exigir la reparación o la sustitución y en los casos en que estas no se hubieran llevado a cabo en plazo razonable o sin mayores inconvenientes para el consumidor y usuario. La resolución no procederá cuando la falta de conformidad sea de escasa importancia”.

¿Qué conclusión se sigue del juego de todos estos artículos? La respuesta es que en el ámbito español -en general en el europeo- la garantía convencional no puede limitar los derechos que reconoce la garantía legal al consumidor. Eso es perfectamente correcto, sin embargo, al considerar las normas pertinentes se descubre que, en el derecho español, la garantía legal se encuentra estructurada jerárquicamente, en términos que, por regla general, el consumidor únicamente puede optar por la reparación o sustitución del producto y, excepcionalmente, cuando estas sean objetivamente imposibles, económicamente desproporcionadas o no se hubieran llevado a cabo dentro de un plazo razonable o hayan existido inconvenientes podrá optar por la resolución o la rebaja del precio.

Pues bien, al observar estas normas se descubre, según me parece, que no necesariamente resulta absurdo que, en el ámbito nacional, la garantía convencional pueda limitar la opción que le confiere al consumidor la garantía legal. Y no resulta absurdo porque, si bien podría estimarse que eso debilita la posición del consumidor y, a la vez, se considera que la Ley $\mathrm{N}^{\circ} 19.496$ aspira a tutelar los derechos de los consumidores, lo cierto es que no procura hacerlo a cualquier costo. Bien podría afirmarse que, como sucede en el ámbito europeo, la tutela del consumidor a este respecto debe conjugarse con una cierta consideración a la posición del proveedor. Por lo mismo, sería el caso que se reconozca a este último la posibilidad de reparar el producto o reemplazarlo.

34 Torrelles, 2011, p. 1091. Como apunta Fenoy, 2009, p. 236, a propósito de algún trabajo preparatorio de la Directiva 99/44: "se constata que se intenta conseguir un equilibrio entre la salvaguarda de la protección del consumidor y la no imposición para el vendedor de buena fe de una carga excesiva". Fenoy se refiere al Libro verde acerca de las garantías de los bienes de consumo y los servicios postventa de 15 de noviembre de 1993 (COM (93) 509 final, 15.11.1993). En la página 92 de este se lee lo siguiente:

"Los efectos tradicionales de la garantía legal son el derecho del comprador a anular el contrato o a obtener una reducción del precio [para el Derecho español, piénsese en el saneamiento por vicios ocultos, añado]. En las modernas relaciones de consumo, estos medios son a la vez demasiado rígidos y demasiado insuficientes. A menudo corren el peligro de no satisfacer ni al consumidor ni al vendedor. Por ello, ciertos sistemas jurídicos se han decidido por fin a introducir, de uno u otro modo, en el marco de la garantía legal, los medios tradicionales de la garantía comercial, a saber, la sustitución o la reparación del bien. Cuando sea posible, debería preferirse la sustitución o la reparación frente a las otras posibles soluciones y esto significaría el contrapunto de una visión más amplia del concepto de 'defecto'. Se trata de esta manera de salvaguardar la protección del consumidor, sin imponer al vendedor de buena fe una carga excesiva”. 
Cuestión que podría justificarse, además, en términos económicos. ${ }^{35}$ Por otra parte, aludiendo, en cambio, a cierta exigencia de justicia, Picatoste justifica la primacía de la reparación señalando que:

“(...) parece justo que al vendedor se le dé la oportunidad de corregir las faltas de conformidad del producto, más aún cuando en la mayor parte de los casos tienen su origen en hechos que, por lo general, están fuera de la esfera de su control”36.

Finalmente, como se ha visto respecto del ámbito español, lo cierto es que una virtud de los remedios de primer grado (reparación y sustitución) respecto de la resolución es que tienden a mantener el contrato ${ }^{37}$.

Como se ha visto, en el ámbito europeo la posibilidad de reparar o reemplazar se encuentra reconocida al proveedor en los términos expuestos a propósito de la garantía legal. En el ámbito chileno, en cambio, el legislador ha sido más severo y le ha impuesto al proveedor la carga de establecerlo en la garantía convencional. La jerarquía de los remedios, entonces, se encuentra, por así decirlo, dispersa entre la garantía legal y la convencional.

En el ámbito nacional, entonces, las cosas funcionarían de la siguiente manera. Si no existe garantía convencional, el consumidor dispone de los remedios de la garantía legal, pudiendo optar por cualquiera de ellos en la medida en que se satisfagan sus requisitos particulares ${ }^{38}$. Si existe una garantía convencional, entonces, antes de acudir a la garantía legal, el consumidor debe hacerla efectiva ante quien corresponde y agotar las posibilidades que ofrece conforme a los términos de la póliza.

Por supuesto, es posible discutir si resulta social o económicamente adecuado o justo preferir al proveedor que al consumidor ${ }^{39}$, pero esa no es la discusión que me interesa ahora. Mi ánimo es más modesto, simplemente quería mostrar que el resultado a que conduce una cierta primacía de la garantía convencional sobre la legal no necesariamente es absurdo.

${ }^{35}$ Así, por ejemplo, Gómez Pomar, 2001, p. 20, señala lo siguiente:

“(...) la prioridad otorgada a la reparación y la sustitución parece razonable. Esto permite a los vendedores explotar economías de escala en reparación (inversión en costosos equipos de reparación, especialización en el trabajo de reparación, grandes stocks de piezas de recambio) y, hasta cierto punto, también en sustitución (grandes stocks de productos). Esto puede contribuir a reducir el coste que supone la garantía para el vendedor y, en consecuencia, beneficiar en último término a los compradores".

36 Picatoste, 2011, p. 206.

37 En el ámbito chileno lo ha señalado respecto de la reparación BARRIENTOs, 2016, p. 171.

38 Así, por ejemplo, para optar por la devolución de la cantidad pagada que, en realidad, corresponde a la resolución del contrato (ver PeÑAllillo, 2003, p. 395), deberá tratarse de un incumplimiento grave. Ver BARRientos, 2016, pp. 202-207.

39 Así, por ejemplo, Howells y Weatherhill, 2005, p. 199, refiriéndose a la Directiva 99/44 señalan que las razones para abandonar la libre elección del consumidor por los remedios y favorecer la reparación y substitución, señalan que se debería a razones más políticas que jurídicas. Como sea que fuere, el hecho es que en Europa parece estar consolidado y, al decir de VAQUER, 2003, p. 550 "ya no cabe esperar demasiadas novedades”. Con todo, habrá que advertir que en el caso portugués, el artículo 4.5 del Decreto 
Antes de abandonar este apartado, conviene explicitar alguna prevención. Su objetivo ha consistido únicamente en mostrar que la comprensión que propongo de la convivencia entre la garantía legal y convencional no necesariamente es absurda y que así lo muestra el derecho europeo. Lo que no pretendo afirmar es que la Directiva 99/44 y el TRLGDCU hayan influido en el legislador chileno en esta materia, pues ambas son posteriores. Mi argumento es, sencillamente, que la interpretación que sustento puede ser razonable si se mira el derecho europeo ${ }^{40}$.

\section{La presencia de dificultades prácticas y los límites de la garantía convencional}

Aún si se acepta que la lectura literal del inciso $9^{\circ}$ del artículo 21 no arroja un resultado absurdo, resta hacerse cargo del argumento en relación con las dificultades prácticas que advierte el profesor Corral respecto de la primacía de la garantía convencional ${ }^{41}$.

En términos más generales, resta hacerse cargo de la afirmación de que se acepte la primacía de la garantía convencional sobre la legal no se sigue que se acepte la primacía de cualquier garantía convencional; aceptarlo de esa manera sacrificaría irreversiblemente la tutela del interés de los consumidores.

Sin embargo, no sucede así, pues, por así decirlo, la jerarquía entre la cláusula convencional y la legal se encontraría temperada por las limitaciones que se establecen a la primera.

Para desarrollar esta idea convendrá comenzar advirtiendo que, no obstante el hecho de que la garantía convencional se encuentre en el contrato que disciplina la adquisición del producto o en un documento separado, su carácter es contractual ${ }^{42}$ y se trata de un contrato de adhesión.

Esta sencilla constatación produce consecuencias extremadamente relevantes respecto de lo que aquí interesa. La primera de ellas es que, como cualquier contrato, para que vincule a las partes ha de ser el caso que estas hayan aceptado sus términos y, para que algo así suceda, ha de ser el caso que el consumidor haya sido suficientemente informado acerca de la existencia de la garantía convencional ${ }^{43}$. Esto no ofrecerá problemas cuando

Lei No 67/2003 establece que el consumidor podrá ejercitar la acción que más le convenga, estableciendo como límites la posibilidad y el abuso del derecho.

La primacía de la reparación también se presenta en algunos países de Latinoamérica. BARRIENTOS, 2016, p. 222 informa que tanto en Argentina como en Colombia prima la reparación y que en el Código de consumo brasileño prima la sustitución de piezas defectuosas.

${ }^{40}$ Con todo, según mi comprensión, el régimen de garantía que establecía el artículo 11 de la Ley General de Consumidores y Usuarios española de 1984 permite defender que el titular de la garantía tenía derecho a la reparación gratuita y, solo en el caso de que la reparación no fuere satisfactoria, a la sustitución o a la devolución del precio pagado. Pues bien, algo como eso, aunque de manera más torpe, es lo que, en mi opinión dispondría la LPC, distribuido entre la regulación de la garantía legal y la convencional.

${ }^{41}$ Corral, 2011, p. 417.

${ }^{42}$ Como apunta Corral, 2011, p. 412 esto no resulta evidente en el caso de las garantías del fabricante, distribuidor o fabricante, pero, como ya ha quedado dicho, en este trabajo mi interés se limita a las garantías del vendedor.

43 Acerca de los deberes de información en la Ley N 19.496 ver DE LA MAZA, 2010b. 
se trate de una garantía extendida por la que el consumidor pague, pero sí podría suscitarlos si se trata de una garantía ofrecida sin necesidad de pago.

Por otra parte, aun cuando se suministre información acerca de la garantía convencional, puede ser que esta no sea suficientemente transparente pues no haga suficientemente explícita información que para el consumidor resulta relevante, por ejemplo, que el único remedio es la reparación ${ }^{44}$.

En segundo lugar -y superados los controles de inclusión y transparencia ${ }^{45}$ - resta examinar si los términos de la garantía resultan o no abusivos según lo dispuesto en el artículo $16^{\circ}$ de la Ley $\mathrm{N}^{\circ} 19.496$.

Como ya ha quedado dicho, en Chile, el problema parece suscitarse, generalmente al menos, porque el consumidor desea la resolución del contrato y la garantía le exige que intente la reparación de la cosa o, con menor frecuencia, su reemplazo ${ }^{46}$. De esta manera, habrá que formularse dos preguntas diversas. La primera es si puede considerarse como abusivo que la garantía le exija la reparación o reemplazo de la cosa. En el evento de que la respuesta a esta pregunta sea negativa, será necesario cuestionarse acerca de en qué condiciones debe ofrecerse la reparación.

Frente a la primera pregunta, la respuesta, en mi opinión, es no. No puede considerarse como abusivo algo que la misma Ley $\mathrm{N}^{\circ} 19.496$ le permite al proveedor. Por supuesto, la corrección de esta respuesta depende de la corrección de la idea de que no existe un derecho irrenunciable a la triple opción que concede la garantía legal que ya he defendido. Si esa defensa cae, también lo hace esta respuesta.

La siguiente pregunta es más interesante ¿bajo qué condiciones debe ofrecer la reparación la garantía convencional? La respuesta que ofrezco es que no puede ser bajo condiciones inferiores a las que la garantía legal ofrece este remedio.

La razón es lo siguiente. No resulta dudoso que el consumidor tiene un derecho a que le reparen la cosa y que ese derecho es irrenunciable. Tampoco debería dudarse que esa irrenunciabilidad no se encuentra cualificada por el artículo 21 inciso $9^{\circ}$. De esta manera, parece correcto afirmar que ofrecer en la garantía convencional la reparación en términos inferiores a los que se establecen a propósito de la garantía legal equivale a una renuncia parcial al derecho de reparación ${ }^{47}$.

De esta manera, preguntarse acerca de las condiciones bajo las que se debe ofrecer la reparación en una garantía convencional (y, por tanto, cuáles son sus límites) exige considerar en qué condiciones debe proceder cuando se trata de la garantía convencional.

${ }^{44}$ Quizás esto podría explicar la paradoja que, correctamente advierte el profesor CorRAL, 2011, p. 417 que una persona pague por una garantía extendida que, en definitiva, disminuye su protección. Probablemente, esas cláusulas se expliquen por su falta de transparencia y, por lo mismo, no vinculan al consumidor.

45 Acerca del requisito de la transparencia puede consultarse, en general, Loos, 2015, pp. 180.

${ }^{46}$ Así, por ejemplo, en la sentencia de la Corte de Apelaciones de Rancagua, 22.11.2011, rol 93-2011.

47 Cuestión, por supuesto, distinta es que el ejercicio de ese derecho esté sujeto a ciertos límites. Referente al punto ver BARrientos, 2016, pp. 179-185. 
De este tema se ha ocupado con acierto, según me parece, la profesora Francisca Barrientos, por tanto, en general, se pueden seguir sus ideas ${ }^{48}$. De esta manera, su ejercicio es extrajudicial, por otra parte, como lo dispone el artículo 20 de la Ley Nº 19.496 la reparación deberá ser gratuita. En tercer lugar, esta vez se trata del inciso sexto del artículo 21 el, remedio se reclama en el mismo local donde se efectuó la venta o en las oficinas o locales en que habitualmente atiende a sus clientes, no pudiendo condicionar el ejercicio de los referidos derechos a efectuarse en otros lugares ${ }^{49}$. El mismo inciso establece una cuarta condición y es que la reparación no puede ofrecerse en condiciones menos cómodas para el consumidor que las que se le ofreció para efectuar la venta, salvo que este consienta en ello. En quinto, debe ser dentro de un plazo razonable. Si bien la Ley $\mathrm{N}^{0} 19.496$ no explicita este requisito, así lo ha entendido la doctrina ${ }^{50}$ y los tribunales ${ }^{51}$. Respecto de cómo determinar si el plazo es razonable parece útil prestar

48 BARRIENTOS, 2016, pp. 174-185.

${ }^{49}$ Respecto de la gratuidad y el lugar en que se deben efectuar las reparaciones, la sentencia de la Corte de Apelaciones de Concepción de 9 de junio de 2015 (Gaete Avilés con Comercial [2015]) conoce de la venta de un motor fuera de borda defectuoso respecto del cual el consumidor intentó hacer efectiva la garantía. Sin embargo, se le quiso cobrar y enviar el motor desde Concepción a Santiago. La Corte estimó lo siguiente:

"Que por otra parte, y conforme al artículo 21 de la Ley referida, el consumidor se encuentra dentro del plazo que lo ampara la garantía del producto y agotó las posibilidades que le otorga el proveedor y el servicio técnico designado por aquél, puesto que como ya se dijo, ellos rechazaron la reparación gratuita en razón de la mencionada garantía del producto.

Sobre este particular, ha de considerarse, asimismo, que además de no realizar una reparación gratuita conforme a las condiciones propias de una garantía, la misma tampoco fue efectuada dentro de un plazo razonable que resguardara los derechos del consumidor, a fin de que éste hiciere uso y goce del bien que adquirió, plazo que no se encuentra establecido en el propio texto legal, lo que hacía necesario recurrir a las cláusulas contenidas en la póliza de garantía propia de la operación de compra de una especie como la señalada, la que no se acompañó por ninguna de las partes, correspondiendo al proveedor acreditar y probar que dio respuesta oportuna y cabal a los requerimientos efectuados por el denunciante, lo que en definitiva no hizo.)

Que al respecto, y en todo caso, valga considerar que tratándose de la compra de un motor nuevo y sin uso, resulta atentatorio a las normas que regulan la protección a los derechos de lo consumidores, considerar que el cliente deba aceptar pagar la reparación de las piezas dañadas viajar a la ciudad de Concepción y a Santiago para poder obtener dicha reparación, debiendo soportar que se le privara del uso del motor, que además constituye su fuente de trabajo, mientras durara su reparación, siendo plausible suponer que tales conductas igualmente vulneran el derecho de la querellante contenido en el artículo $3^{\circ}$ de la Ley del Consumidor y la obligación contenida en el artículo 23 inciso $1^{\circ}$ de la misma norma legal”.

${ }^{50}$ BARrientos, 2016, pp. 181-182.

${ }^{51}$ Así, por ejemplo, Corte de Apelaciones de Concepción, 5.11.2013, rol 206-2013, conociendo de la venta de un vehículo con desperfectos, consideró que:

“Al respecto, y en todo caso, valga considerar que tratándose de la compra de un vehículo nuevo y sin uso resulta atentatorio a las normas que regulan la protección a los derechos de los consumidores, considerar que el cliente deba aceptar la reparación de una pieza dañada, lo que incluso importaba desmontar el motor entero; que debiera esperar por espacio de un mes que llegara el repuesto desde Corea o que debiera soportar que se le privara del uso del vehículo mientras durara su reparación, siendo plausible suponer que, teniendo la falla su origen en las dependencias del proveedor o en la fabricación del producto, tales conductas igualmente vulneran el derecho de la querellante contenido en el artículo $3^{\circ}$ de la Ley del Consumidor y la obligación contenida en el artículo 23 inciso $1^{\circ}$ de la misma norma legal”. 
atención a lo dispuesto en el artículo 120 letra b) del TRLGDCU, según este, la reparación o sustitución del producto:

"Deberán llevarse a cabo en un plazo razonable y sin mayores inconvenientes para el consumidor y usuario, habida cuenta de la naturaleza de los productos y de la finalidad que tuvieran para el consumidor y usuario".

En séptimo lugar, únicamente puede exigirse al consumidor que solicite una vez la reparación y si subsistieren las deficiencias o bien se presentaran nuevas, entonces quedará a su disposición la triple opción que confiere la garantía legal. Esa es, al menos, mi comprensión de lo dispuesto en el artículo 20 letra e) de la Ley $\mathrm{N}^{\circ} 19.496 .52$ Por tanto, el agotamiento de la póliza al que alude el inciso $9^{\circ}$ del artículo $21^{\circ}$ se cumple de esa manera. Creo que, a todo esto, aún podría agregarse que no puede establecer limitaciones al derecho a obtener una indemnización más allá de lo que permiten dichas limitaciones el sorprendente artículo 16 la letra e) de la Ley $\mathrm{N}^{\circ} 19.496^{53}$.

Pues bien, si la garantía convencional se encuentra redactada en términos abusivos el consumidor podrá solicitar su nulidad y quedarán a su completa disposición todos los remedios de la garantía legal.

La segunda situación que puede tener lugar -y que parece darse con cierta frecuencia- es que si bien los términos de la garantía no se encuentren redactados de manera abusiva, su ejercicio por parte del proveedor sí lo sea, reservándose, por ejemplo, largos plazos para la reparación. En un escenario como ese parece razonable pensar que también debe estimarse que el consumidor agotó los términos de la garantía convencional y puede acudir a la legal. Y resulta razonable pensarlo de esta manera porque en la lectura que he ofrecido la jerarquía de la garantía convencional protege al proveedor, pero, si este la ejerce de manera incorrecta, por así decirlo, se hace indigno de dicha protección ${ }^{54}$.

52 En ocasiones los tribunales lo han entendido de esta manera, advirtiendo que el consumidor puede acudir a la garantía legal luego de que llevando la cosa a reparación al servicio técnico los desperfectos se han mantenido. En este sentido puede consultarse la sentencia de la Corte de Apelaciones de Copiapó, 29.08.2008, rol 23-2008. En el mismo sentido, la sentencia de la Corte de Apelaciones de Antofagasta, 14.05.2013, rol 264-2012, respecto de una persona que llevó su automóvil al servicio técnico ejerciendo la garantía legal, sin embargo, las deficiencias subsistieron. La opinión de la Corte fue la siguiente:

"Que acreditado que el denunciado ha actuado con negligencia al entregar un vehículo no apto para su uso normal, sin inconvenientes y que luego de hacerse efectiva la garantía los defectos se mantuvieron, solo cabe concluir que en la especie se configuraron las situaciones previstas en las letras c) y e) del artículo 20 de la Ley del Consumidor, pues la camioneta ha presentado deficiencias de fabricación, de partes y piezas, que hicieron que no fuera enteramente apta para el uso a la que estaba destinada, asimismo, después de la primera vez de haberse hecho efectiva la garantía y prestado el servicio técnico correspondiente, subsistieren las deficiencias que hacían al bien inapto para el uso ya referido, por lo que nace para el comprador el derecho a optar entre la reparación gratuita del bien o, previa restitución, su reposición o la devolución de la cantidad pagada, sin perjuicio de la indemnización por los daños ocasionados".

En el mismo sentido ver sentencia de la Corte de Apelaciones de Antofagasta, 20.03.2013, rol 251-2012.

53 Una crítica al literal en TAPiA Y VALdivia, 2002, pp. 80-91.

${ }^{54}$ Mutatis mutandis esta es la solución a la que llega el artículo 121 del TRLGDCU. 
Quizás esa sea una posible lectura de una sentencia que la profesora Barrientos ${ }^{55}$ y el profesor Corral $^{56}$ citan para apoyar la primacía de la garantía legal sobre la convencional. Se trata de la sentencia de la Corte Suprema de 23 de marzo de $2010^{57}$.

\section{CONCLuSiones}

En primer lugar no parece sensato aceptar ni que el consumidor siempre tiene a su disposición la opción por cualquiera de los remedios que le reconoce la garantía legal ni que siempre la existencia de una garantía convencional lo prive de los remedios de segundo orden, es decir, la reducción del precio y, sobre todo, la resolución del contrato.

En segundo lugar, los argumentos que parecen justificar la primacía de la garantía legal no parecen completamente persuasivos. Respecto de la irrenunciabilidad, la primacía de la garantía convencional.

En tercer lugar, al prestar atención al argumento del absurdo y al de las dificultades prácticas se descubren un par de cuestiones que vale la pena recordar. La primera de ellas es que resulta posible una lectura de que la primacía de la cláusula convencional por sobre la legal no es absurda. Según esta lectura, al considerar en conjunto la cláusula legal y la convencional se descubre una cierta jerarquía de remedios que, al menos en el ámbito europeo, se ha considerado razonable. Cuestión distinta es, por supuesto, que en el ámbito nacional el legislador haya plasmado esa jerarquía de una forma tan peculiar. En tercer lugar, revisitando el argumento de las dificultades prácticas es posible constatar que el profesor Corral lleva razón en que existen dificultades prácticas. Pero la presencia de esas dificultades no constituye, en mi opinión al menos, un buen argumento para justificar la primacía de la garantía legal en términos de que la opción siempre se encuentre disponible para el consumidor. Es un buen argumento, en cambio, para justificar la vigencia de importantes limitaciones a los términos de la garantía convencional.

\section{BIBLIOGRAFÍA}

Aimone, Enrique, 2013, Protección de Derechos del Consumidor, Thomson Reuters, Santiago.

Álvarez, María Teresa, 2006, "La garantía comercial", en S. Díaz Alabart (coord.), Garantía en la venta de bienes de consumo (Ley 23/2003, de 10 de julio), Edisofer, Madrid,

Avilés García, Javier, 2009, "Contratos, información, garantías y prácticas comerciales desleales", en Revista de Derecho Privado, 93-3.

Barrientos, Francisca, 2016, La garantía legal, Thomson Reuters, Santiago.

\footnotetext{
55 BARrientos, 2016, p. 251.

56 Corral, 2011, p. 424.

${ }^{57}$ Corte Suprema, 23.03.2010, rol 9357-2010.
} 
Corral, Hernán, 2011, "Relaciones entre la 'garantía legal' y la garantía voluntaria del proveedor en la Ley de protección de los Derechos del Consumidor”, en F. Elorriaga de Bonis (coord.), Estudios de Derecho Civil VII, Thomson Reuters, Santiago, pp. 409-425.

De la MAZA, Íñigo, 2012, "El régimen de los cumplimientos defectuosos en la compraventa", en Revista Chilena de Derecho, Vol. 39 No 3, pp. 629-663.

De la MAZA, Íñigo 2010a, Los límites del deber precontractual de informar, Thomson Reuters, Cizúr Menor (Navarra).

De la MAZa, Íñigo 2010b, "El suministro de información como técnica de protección de los consumidores: los deberes precontractuales de información”. RDUCN, 2010, Vol. 17, No 2, pp. 21-52.

Ehmann, Horst y Sutschet, Holger, 2006, La reforma del BGB modernización del Derecho alemán de obligaciones, Universidad del Externado de Colombia, Bogotá.

Fenoy, Nives, 2009, El sistema de protección del comprador, Fundación Registral, Madrid.

Fernández, Francisco, 2003, Manual del Derecho Chileno de protección al consumidor, Thomson Reuters, Santiago.

Ferrante, Alfredo, 2018, "Una revisión de los remedios del consumidor chileno en la compraventa con disconformidad a partir de la diferencia entre obligación y garantía". Revista de Derecho Privado. 35, Bogotá.

Gómez, Fernando, 2001, "Directiva 1999/44/CE sobre determinados aspectos de la venta y las garantías de los bienes de consumo: una perspectiva económica”, en InDret 2001.

Howells, Geraint y Weatherhill, Shephen, 2005, Consumer Protection Law, Ashgate, UK.

Loos, Marco, 2015, Transparency of standard terms under the Unfair Contract Terms Directive and the proposal for a common European sales law". European Review of Private Law, 23 (2): I79-I93. Disponible en HTTP://BIT.LY/2XKYUm4.

LORENZINi BARría; JAIme (2015), “Aspectos relevantes de la garantía legal en la ley de protección al consumidor”, en Estudios de Derecho Civil XI, Thomson Reuters, Santiago.

Peñailillo, Daniel, 2003, Las obligaciones, Editorial Jurídica de Chile, Santiago.

Picatoste, Victoria, 2011, La protección de los consumidores en la compraventa de vehículos automóviles, Thomson Reuters, Cizúr Menor, Navarra.

Sandoval, Ricardo, 2016, Derecho Comercial, Tomo V, Editorial Jurídica de Chile, Santiago.

Tapia, Mauricio, Valdivia, José Miguel, 2002, Contratos por Adhesión Ley $N^{o} 19.496$, Editorial Jurídica de Chile, Santiago.

Torrelles, Esther, 2011, "Comentario artículo 118”, "Comentario artículo 119”, "Comentario artículo 120” y “Comentario artículo 125”, en S. Cámara Lapuente (ed.), Comentarios a las normas de protección de los consumidores, Colex, Madrid.

Vaquer, Antoni, 2003, "Incumplimiento del contrato y remedios”, en S. Cámara Lapuente (coord.), AA.VV, Derecho privado europeo, Colex, Madrid. 
